\title{
The effect of overexpression of the HOXD10 gene on the malignant proliferation, invasion, and tumor formation of pancreatic cancer cell PANC-1
}

\author{
Zhijie Lin ${ }^{1,2}$, Yumei $\mathrm{Hu}^{3}$, Ruiyin $\operatorname{Lin}^{2}$, Hua Ye $\mathrm{Y}^{1,4}$ \\ ${ }^{1}$ Department of Epidemiology and Health Statistics, College of Public Health, Zhengzhou University, Zhengzhou 450001, China; ${ }^{2}$ The Second \\ Department outside Anyang Oncology Hospital, Anyang 450000, China; ${ }^{3}$ Anyang Zhonguo Oral Clinic, Anyang 450000, China; ${ }^{4}$ HenanKey \\ Laboratory of Tumor Epidemiology, Zhengzhou 450001, China \\ Contributions: (I) Conception and design: Z Lin, H Ye; (II) Administrative support: R Lin; (III) Provision of study materials or patients: Z Lin, Y Hu, \\ R Lin; (IV) Collection and assembly of data: All authors; (V) Data analysis and interpretation: Z Lin, H Ye; (VI) Manuscript writing: All authors; (VII) \\ Final approval of manuscript: All authors. \\ Correspondence to: Hua Ye. Department of Epidemiology and Health Statistics, College of Public Health, Zhengzhou University, No. 100 Kexue \\ Avenue, Zhengzhou 450001, China. Email: yehuayhh@126.com.
}

\begin{abstract}
Background: To determine the role of HOXD10 in pancreatic cancer.
Methods: A stable HOXD10-expressing PANC-1 cell line was established. Proliferation rates were detected by 5 -Ethynyl-2'-deoxyuridine (Edu) staining while invasion was evaluated by Transwell assay. The expression levels of different proteins were analyzed by Western blotting. A subcutaneous xenograft of pancreatic cancer was established in nude mice, and the tumor weight and body weight were monitored. The in-situ expression of relevant markers in the tumor tissues was detected by immunohistochemistry.

Results: HOXD10 overexpression significantly decreased the proliferation rates of PANC-1 cells, and down-regulated Ki67 and Survivin $(\mathrm{P}<0.05)$. In addition, the invasive capacity $(\mathrm{P}<0.05)$ and the levels of vascular endothelial growth factor $(\mathrm{VEGF})$ and $\mathrm{MMP}-14$ were also significantly decreased $(\mathrm{P}<0.05)$ in the cells overexpressing HOXD10. Consistent with this, high levels of HOXD10 were associated with an increase in $\mathrm{E}$-cadherin $(\mathrm{P}<0.05)$ and a decrease in $\mathrm{N}$-cadherin $(\mathrm{P}<0.05)$ expression. Furthermore, the HOXD10-overexpressing xenografts were significantly smaller $(\mathrm{P}<0.05)$ and had fewer Ki67, VEGF, and $\mathrm{N}$-cadherin-positive cells $(\mathrm{P}<0.05)$.
\end{abstract}

Conclusions: HOXD10 acts as a tumor suppressor in pancreatic cancer, and inhibits the proliferation, invasion, and epithelial-mesenchymal transition of the tumor cells.

Keywords: Pancreatic cancer; HOXD10; malignant biological behavior; epithelial-mesenchymal transition

Submitted Feb 07, 2020. Accepted for publication Mar 06, 2020.

doi: 10.21037 /gs.2020.03.28

View this article at: http://dx.doi.org/10.21037/gs.2020.03.28

\section{Introduction}

Pancreatic cancer is a malignancy of the digestive system, with steadily increasing global incidence and a dismal 5 -year survival rate (1). The outcomes of immunotherapy, surgery and radiation therapy have so far been unsatisfactory due to the considerable side effects (2). Therefore, it is necessary to identify novel therapeutic targets in order to improve patient prognosis. The homeobox (Hox) family members function as oncogenes or tumor suppressors across different cancer types (3). Among these, HOXD10 is an inhibitor of tumor metastasis (4), and is significantly down-regulated in breast cancer, glioma, gastric cancer and liver cancer (5-8). However, its expression levels and pathological relevance in pancreatic cancer have thus far not been reported. The aim of this study was to determine the influence of HOXD10 on the proliferation, invasion, and tumor forming capacity of 
pancreatic cancer cells.

\section{Methods}

\section{Experimental reagents}

Dulbecco's modified Eagle's medium (DMEM; 12100-046), fetal bovine serum (FBS; 10082-147), trypsin (25200-056), and penicillin-streptomycin (15140-122) were purchased from Gibco, USA. The bicinchoninic acid assay (BCA) kit (P0012S) was purchased from Shanghai Beyotime Biotechnology Institute, and Transwell inserts (3374) were acquired from Corning, USA.

\section{Cell culture and transfection}

Human pancreatic cancer tumor cell line PANC-1 was obtained from the Cell Bank of the Typical Culture Preservation Committee of the Chinese Academy of Sciences. The cells were cultured in a high-glucose DMEM supplemented with $10 \%$ FBS and $1 \%$ penicillinstreptomycin at $37{ }^{\circ} \mathrm{C}$ under $5 \% \mathrm{CO}_{2}$. The medium was changed every 2-3 days, and the cells were harvested with $0.25 \%$ trypsin at the logarithmic growth phase for various assays. The cells were seeded into a 6-well plate at the density of $5 \times 10^{5} /$ well, and cultured for $24 \mathrm{~h}$ until they reached $80 \%$ confluency. They were then, transfected with the HOXD10 construct or the empty pcDNA plasmid using LipofecamineTM2000 as per the manufacturer's instructions (9).

\section{Reverse transcription polymerase chain reaction (RT-PCR)}

Total RNA was extracted from PANC-1 cells using Trizol, and the A260/A280 was measured with a NanoDrop spectrophotometer. Reverse transcription and polymerase chain reaction (PCR) were conducted according to the kit instructions. The reaction conditions included predenaturation at $94{ }^{\circ} \mathrm{C}$ for $5 \mathrm{~min}, 35$ cycles of denaturation at $94{ }^{\circ} \mathrm{C}$ for $30 \mathrm{~s}$, annealing at $55^{\circ} \mathrm{C}$ for $30 \mathrm{~s}$, extension at $72{ }^{\circ} \mathrm{C}$ for $30 \mathrm{~s}$, and final extension at $72{ }^{\circ} \mathrm{C}$ for $10 \mathrm{~min}$. The amplified products were analyzed by $2 \%$ agarose gel electrophoresis.

\section{5-Ethynyl-2'-deoxyuridine (Edu) staining}

The PANC-1 cells were seeded into a 96-well plate at the density of $1 \times 10^{5} /$ well, and cultured overnight. The medium was replaced with $100 \mu \mathrm{L}$ fresh medium supplemented with $50 \mu 5$-Edu per well, and the cells were incubated for $2 \mathrm{~h}$. After washing twice with PBS, the cells were fixed and stained, and observed under a fluorescence microscope.

\section{Transwell assay}

The Transwell inserts were coated with Matrigelin serumfree medium at $37^{\circ} \mathrm{C}$ for $5 \mathrm{~h}$. The suitably treated PANC1 cells were seeded into the upper chambers in $100 \mu \mathrm{L}$ serum-free medium per well, and the lower chambers were filled with $600 \mu \mathrm{L}$ medium supplemented with $20 \%$ FBS. After a $24 \mathrm{~h}$ culture, the Transwell inserts were removed and washed twice with PBS, fixed with 5\% glutaraldehyde, stained with $0.1 \%$ crystal violet for $30 \mathrm{~min}$, and observed under a fluorescence microscope.

\section{Establishment of xenograft model}

Nude mice were anesthetized by intraperitoneal injection of $1 \%$ sodium pentobarbital, and inoculated subcutaneously with $1 \times 10^{6}$ control or HOXD10-overexpressing PANC-1 cells in $100 \mu \mathrm{L}$ medium (5 per group). The tumor nodules were measured every day, and the mice were weighed every 5 days. Thirty days after inoculation, the mice were sacrificed, and the tumors were harvested and weighed.

\section{Immunobistochemistry}

Tumor tissues were embedded in paraffin and cut into thin sections. After routine de-waxing, the sections were heated in citrate buffer solution at $95^{\circ} \mathrm{C}$ for $10 \mathrm{~min}$, cooled to room temperature, and incubated with $3 \%$ hydrogen peroxide for $10 \mathrm{~min}$. The sections were then washed 3 times with PBS, blocked with $5 \%$ BSA at $37{ }^{\circ} \mathrm{C}$ for $30 \mathrm{~min}$, and incubated with primary antibodies against HOXD10 (ab172865), Ki67 (ab15580), Survivin (ab76424), vascular endothelial growth factor(VEGF) (ab2350), MMP-14 (ab3644), E-cadherin (ab15148), N-cadherin (ab18203), and actin (ab8227) (all from Abcam, USA) at $37^{\circ} \mathrm{C}$ for $1 \mathrm{~h}$. After washing 3 times with phosphate-buffered saline (PBS), the sections were incubated with biotin-labeled secondary antibody at $37^{\circ} \mathrm{C}$ for $30 \mathrm{~min}$, washed again as described, and incubated with the SABC reagent at $37^{\circ} \mathrm{C}$ for $30 \mathrm{~min}$. Following the final washing step, color was developed using 3, 3'-Diaminobenzidine (DAB), and the sections were counter-stained with hematoxylin, dehydrated, cleared, and sealed with neutral gum. The percentage of immuno- 
positive cells was analyzed by Image J.

\section{Statistical analysis}

All data were analyzed by the SPSS17.0 software and expressed as mean $\pm \mathrm{SD}$. The groups were compared by analysis of variance, and $\mathrm{P}<0.05$ was considered statistically significant.

\section{Results}

\section{HOXD10 overexpression inhibited the growth and invasion of PANC-1 in vitro}

The biological role of HOXD10 in pancreatic cancer cells was determined by ectopically expressing the gene in PANC-1 cells (Figure 1). As shown in Figure 2A,
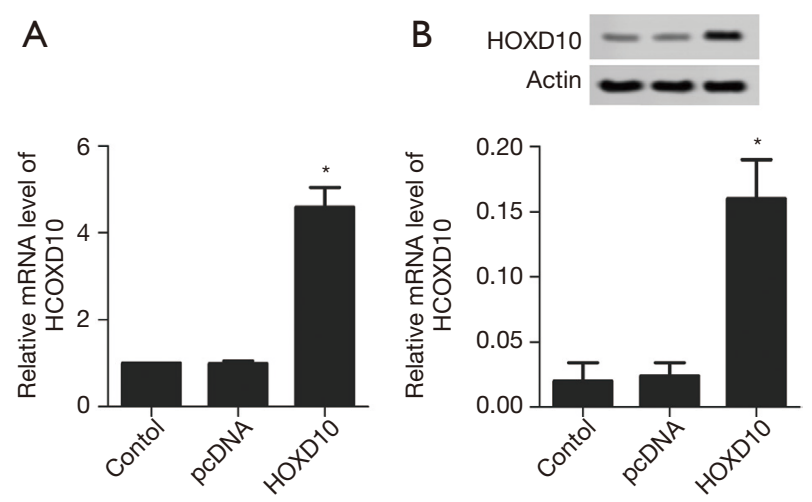

Figure 1 Validation of pcDNA-HOXD10 transfection in PANC1 cells. HOXD10 mRNA (A) and protein (B) levels in the control and HOXD10-overexpressing cells were tested. *, $\mathrm{P}<0.05$ with $t$-test, data are shown as mean \pm SEM of at least 3 replicates. the percentage of EDU-positive proliferating cells was significantly lower in the HOXD10 group compared to the control group $(\mathrm{P}<0.05)$, which correlated to a marked decline in the levels of Ki67 and Survivin $(\mathrm{P}<0.05$; Figure $2 A, B)$. Furthermore, HOXD10 overexpression significantly decreased the proportion of invasive cells $(\mathrm{P}<0.05$; Figure $3 A)$, in addition to down-regulation of VEGF and MMP-14 $(\mathrm{P}<0.05$; Figure $3 B, C)$. Consistent with this, E-cadherin levels were significantly increased in the HOXD10-overexpressing cells $(\mathrm{P}<0.05$, Figure 4), while that of $\mathrm{N}$-cadherin was significantly decreased $(\mathrm{P}<0.05$, Figure 4), indicating epithelial-to-mesenchymal transition (EMT) inhibition.

\section{HOXD10 overexpression inbibited the growth of PANC-1 xenografts}

Compared to the control group, the HOXD10overexpressing tumors were significantly smaller $(\mathrm{P}<0.05$; Figure $5 A, B)$, whereas the body weight of the tumor-bearing mice were similar in both groups (Figure 5C). Consistent with this, the number of Ki67, VEGF, and N-cadherin positive cells were significantly greater in the HOXD10 versus control tumor tissues $(\mathrm{P}<0.05$; Figure $5 D)$.

\section{Discussion}

The Hox gene superfamily encodes transcription factors regulating differentiation and morphogenesis-related genes (10) and is frequently dysregulated during tumorigenesis and metastasis (11). HOXD10 is an established tumor suppressor, although its role in pancreatic cancer has not been reported previously. We
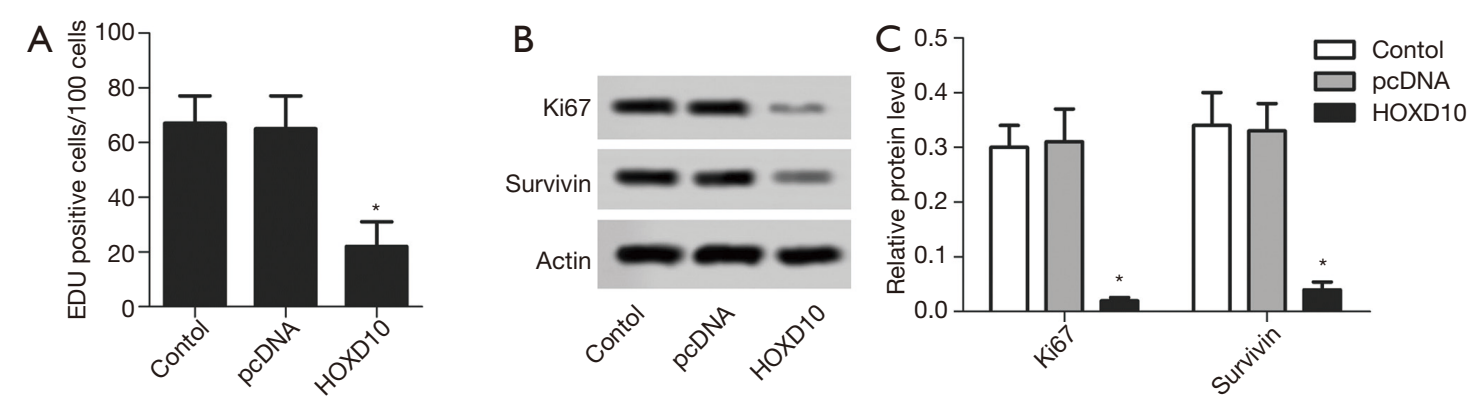

Figure 2 Cell proliferation in HOXD10 transectd PANC-1 cells. (A) Percentage of proliferating PANC-1 cells in the indicated groups. Ki67 and Survivin levels in the control and HOXD10 cells were tested with western blotting (B) and semi-quantified (C). *, P<0.05 with $t$-test, data are shown as mean \pm SEM of at least 3 replicates. 

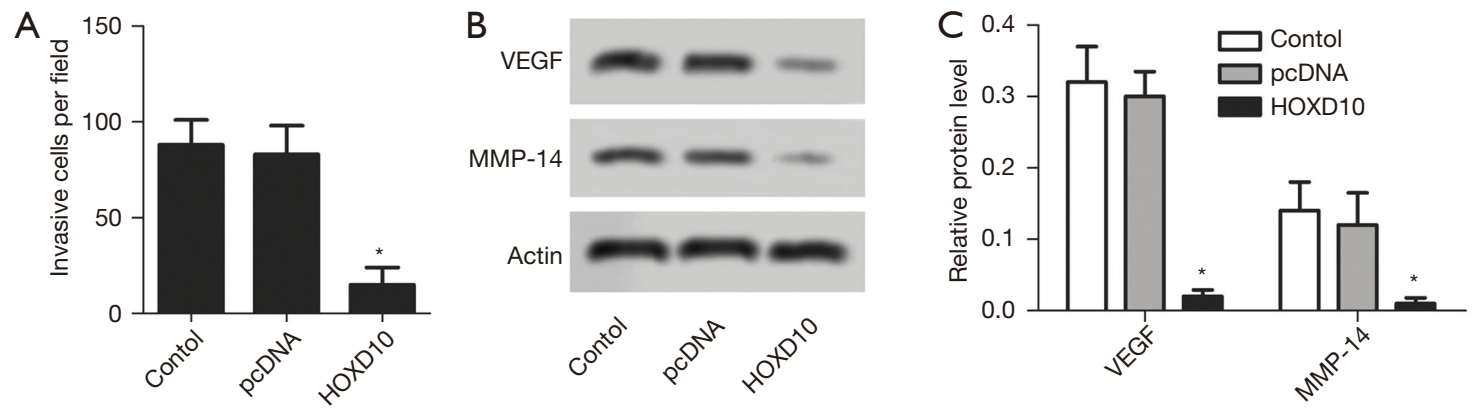

Figure 3 Cell invasion in HOXD10 transectd PANC-1 cells. (A) The proportion of invading cells in the control and HOXD10 groups tested with transwell assay. (B,C) VEGF and MMP-14 expression levels in the indicated groups. *, $\mathrm{P}<0.05$ with $t$-test, data are shown as mean \pm SEM of at least 3 replicates. VEGF, vascular endothelial growth factor.
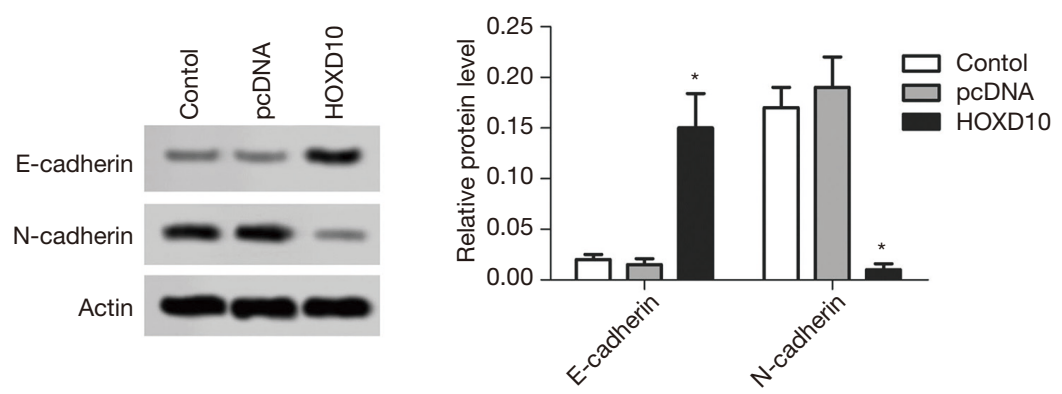

Figure 4 E-cadherin and N-cadherin levels in the control and HOXD10-overexpressing PANC-1 cells. *, P<0.05 with $t$-test, data are shown as mean \pm SEM of at least 3 replicates.

found that HOXD10 expression significantly decreased the proliferation rates and invasiveness of pancreatic cells in vitro and in vivo, indicating that it acts as a tumor suppressor.

Uncontrolled cell proliferation is a hallmark of cancer, and is accompanied by a surge in the expression of Ki67, which is in fact a prognostic indicator for pancreatic cancer (12). Survivin, an anti-apoptotic protein that enhances tumor cell proliferation and infiltration, is also highly expressed in pancreatic cancer tissues (13). We found that both survival-related factors were up-regulated in the PANC1 cells, and decreased significantly upon ectopic expression of HOXD10. Therefore, unsurprisingly, the PANC-1 cells overexpressing HOXD10 also formed smaller tumors in vivo. This is consistent with the finding of Yang et al. (14) in whichHOXD10 overexpression significantly reduced the colony forming ability of bile duct cancer cells. In addition, high levels of HOXD10 significantly inhibited the proliferation of the human hepatobiliary carcinoma RBE and HCCC-9810 cell lines (15).
Metastasis is a critical factor determining cancerrelated mortality (16), and depends on multiple factors. For instance, high levels of VEGF induce angiogenesis and improve tumor vascular permeability, thereby facilitating tumor cell entry into circulation and eventual metastasis (17). VEGF is frequently overexpressed in pancreatic cancer tissues compared to the normal adjacent tissues (18). MMP-14, a member of the matrix metalloproteinase family, is also aberrantly expressed in cancer and promotes tumor cell metastasis (19). In pancreatic cancer, MMP14 further activates MMP-2 and MMP-9, which correlate to greater invasion and metastasis (20). Xi et al. (21) found that HOXD10overexpression in colorectal cancer cells significantly decreased VEGF levels and retarded tumor growth. Consistent with this, Jin et al. (22) found that overexpression of HOXD10 significantly inhibited the invasiveness of nasopharyngeal carcinoma cells. We found that HOXD10 significantly down-regulated VEGF and MMP-14 in PANC-1 cells, and decreased the number of VEGF-positive cells in the xenografts, indicating that 

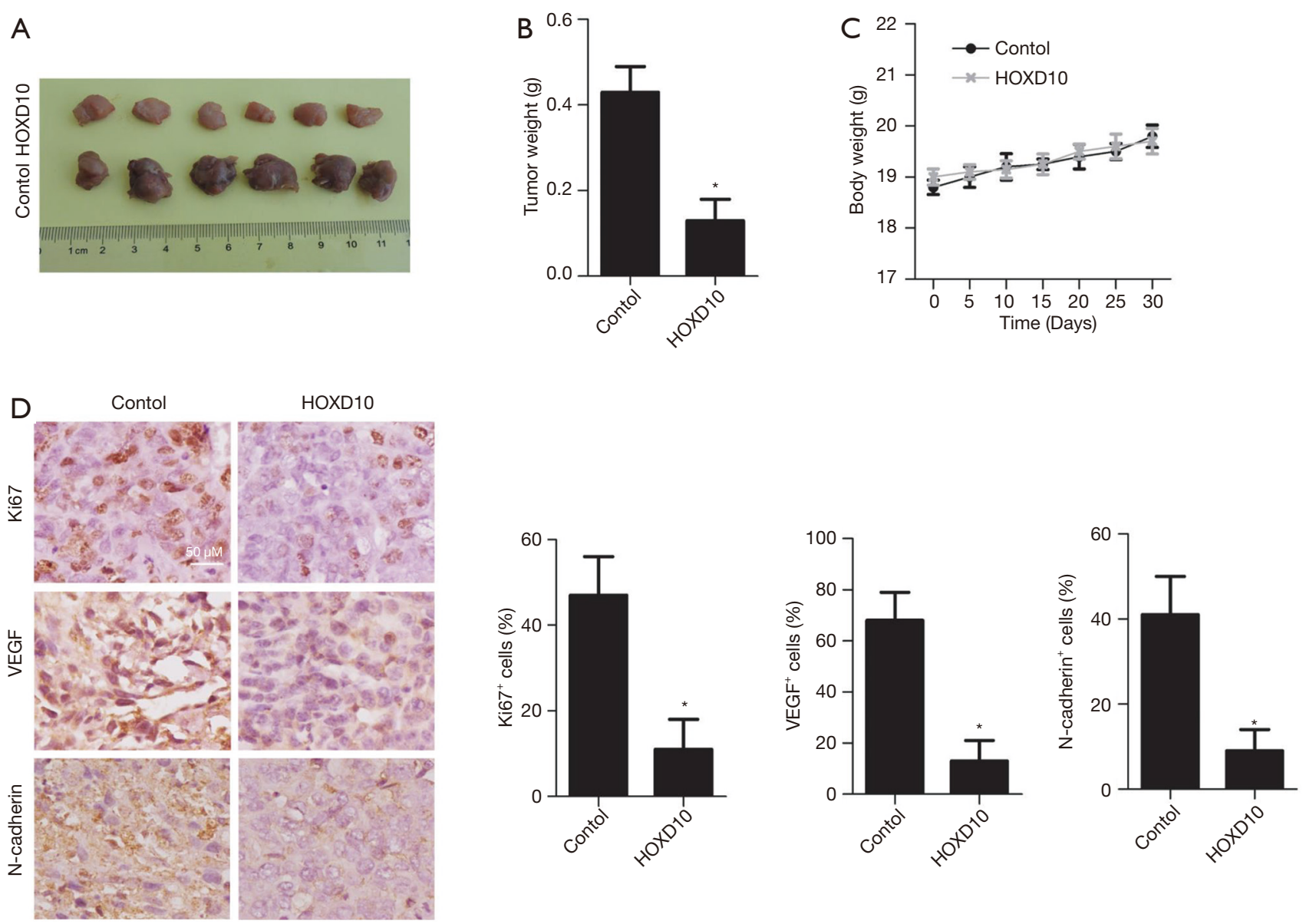

Figure 5 Effects of HOXD10 overexpression in PANC-1 xenograft mice. (A,B) Tumor weight and volume in the control and HOXD10 groups. (C) Body weight of the mice in different groups. (D) Ki67, VEGF, and N-cadherin expression levels in the control and HOXD10 xenografts. * $\mathrm{P}<0.05$ with $t$ test, data are shown as mean \pm SEM of at least 3 replicates. VEGF, vascular endothelial growth factor.

HOXD10 can inhibit the invasion of pancreatic cancer cells.

EMT, or the transformation of epithelial cells into mesenchymal cells, is a key driver of metastasis since it endows the tumor cells with greater motility and invasiveness. Therefore, increased EMT of tumor cells is indicative of poor prognosis (23). At the molecular level, EMT is characterized by the down-regulation of E-cadherin and a concomitant increase in $\mathrm{N}$-cadherin levels (24). HOXD10 significantly up-regulated E-cadherin and downregulated $\mathrm{N}$-cadherin in the PANC-1 cells, indicating that it likely inhibits the EMT and metastasis of pancreatic cancer cells.

In summary, HOXD10 overexpression inhibited the proliferation, invasion, EMT, and in vivo expansion of
PANC-1 cells, indicating its potential as a therapeutic target in pancreatic cancer.

\section{Acknowledgments}

Funding: None.

\section{Footnote}

Conflicts of Interest: All authors have completed the ICMJE uniform disclosure form (available at http://dx.doi. org/10.21037/gs.2020.03.28). The authors have no conflicts of interest to declare.

Ethical Statement: The authors are accountable for all 
aspects of the work in ensuring that questions related to the accuracy or integrity of any part of the work are appropriately investigated and resolved.

Open Access Statement: This is an Open Access article distributed in accordance with the Creative Commons Attribution-NonCommercial-NoDerivs 4.0 International License (CC BY-NC-ND 4.0), which permits the noncommercial replication and distribution of the article with the strict proviso that no changes or edits are made and the original work is properly cited (including links to both the formal publication through the relevant DOI and the license). See: https://creativecommons.org/licenses/by-nc-nd/4.0/.

\section{References}

1. Ciofoaia V, Haddad NG, Smith JP. How many pancreatic cysts are out there and how to best manage them? Transl Cancer Res 2018;7:S500-5.

2. Negoi I, Beuran M, Hostiuc S, et al. Glycosylation alterations in acute pancreatitis and pancreatic cancer: CA19-9 expression is involved in pathogenesis and maybe targeted by therapy. Ann Transl Med 2019;7:S306.

3. Shah N, Sukumar S. The Hox genes and their roles in oncogenesis. Nat Rev Cancer 2010;10:361-71.

4. Xiao H, Li H, Yu G, et al. MicroRNA-10b promotes migration and invasion through KLF4 and HOXD10 in human bladder cancer. Oncol Rep 2014;31:1832-8.

5. Makiyama K, Hamada J, Takada M, et al. Aberrant expression of HOX genes in human invasive breast carcinoma. Oncol Rep 2005;13:673-9.

6. Wang L, Chen S, Xue M, et al. Homeobox D10 gene, a candidate tumor suppressor, is downregulated through promoter hypermethylation and associated with gastric carcinogenesis. Mol Med 2012;18:389-400.

7. Hu X, Chen D, Cui Y, et al. Targeting microRNA-23a to inhibit glioma cell invasion via HOXD10. Sci Rep 2013;3:3423.

8. Li Q, Ding C, Chen C, et al. miR-224 promotion of cell migration and invasion by targeting Homeobox D 10 gene in human hepatocellular carcinoma. J Gastroenterol Hepatol 2014;29:835-42.

9. Hu Q, Li J, Meng H, et al. Effects of RegIV on proliferation, invasion, and migration of pancreatic cancer cells PANC-1. Shandong Medical Journal 2017;57:1-4.

10. Botas J. Control of morphogenesis and differentiation by HOM/Hox genes. Curr Opin Cell Biol 1993;5:1015-22.
11. Yachi K, Tsuda M, Kohsaka S, et al. miR-23a promotes invasion of glioblastoma via HOXD10-regulated glialmesenchymal transition. Signal Transduct Target Ther 2018;3:33.

12. Qin R, Smyrk TC, Reed NR, et al. Combining clinicopathological predictors and molecular biomarkers in the oncogenic K-RAS/Ki67/HIF-1alpha pathway to predict survival in resectable pancreatic cancer. $\mathrm{Br} \mathrm{J}$ Cancer 2015;112:514-22.

13. Wu J, Wang Z, Zhu H. Progress of survivin in pancreatic carcinoma. Journal of Medical Postgraduates 2009;22:306-10.

14. Yang H, Mi J, Yu D, et al. Role of HOXD10 in radiosensitivity of cholangiocarcinoma cells. Tumor 2016;36:986-93.

15. Yang H, Zhou J, Mi J, et al. HOXD10 acts as a tumorsuppressive factor via inhibition of the RHOC/AKT/ MAPK pathway in human cholangiocellular carcinoma. Oncol Rep 2015;34:1681-91.

16. Han $H$, Wang D, Yang $M$, et al. High expression of RACK1 is associated with poor prognosis in patients with pancreatic ductal adenocarcinoma. Oncol Lett 2018;15:2073-8.

17. Zhu DM, Li DC, Zhang ZX, et al. Effect of endothelial PAS domain protein 1 and hypoxia inducible factor 1alpha on vascular endothelial growth factor expression in human pancreatic carcinoma. Chin Med J (Engl) 2008;121:2258-64.

18. Li CL, Cui YF, Du XF, et al. Clinical significance of matrix metalloproteinases-9 and vascular endothelial growth factor expression in the invasion and metastasis of pancreatic carcinoma. World Chinese Journal of Digestology 2008;16:1012-6.

19. Soubani O, Ali AS, Logna F, et al. Re-expression of miR200 by novel approaches regulates the expression of PTEN and MT1-MMP in pancreatic cancer. Carcinogenesis 2012;33:1563-71.

20. Hu B, Zhang K, Li S, et al. HIC1 attenuates invasion and metastasis by inhibiting the IL-6/STAT3 signalling pathway in human pancreatic cancer. Cancer Lett 2016;376:387-98.

21. Xi CL, Gong ZL, Zhou QC, et al. Mechanism of HOXD10 gene inhibiting on growth of colorectal cancer cells. J Chinese Journal of Immunology 2018;34:1804-8.

22. Jin QZ, Meng YY, Huang DD, et al. Adjustment effect of homeobox gene D10 on malignant biological behaviors of 
human nasopharyngeal carcinoma. J Chinese Journal of Health Laboratory Technology 2016;29:1297-300.

23. Ma RR, Gong HB, Gong J, et al. Relationship between epithelial to mesenchymal transition and prognosis in pancreatic cancer. World Chinese Journal of Digestology

Cite this article as: $\mathrm{Lin} \mathrm{Z}, \mathrm{Hu} \mathrm{Y}$, Lin $\mathrm{R}$, Ye $\mathrm{H}$. The effect of overexpression of the HOXD10 gene on the malignant proliferation, invasion, and tumor formation of pancreatic cancer cell PANC-1. Gland Surg 2020;9(2):385-391. doi: 10.21037 /gs.2020.03.28
2016;24:686-91.

24. Gaianigo N, Melisi D, Carbone C. EMT and Treatment Resistance in Pancreatic Cancer. Cancers (Basel)

2017;9:122. 